\section{Weather Prediction from Observation of Gloudlets.}

I was greatly interested in Mr. C. D. Stewart's letter (NATURE, February 20, p. 27o) which expresses my meaning exactly. But I do not know why he should think I regard " as a general method of prediction one which is applicable only in particular conditions, namely, those of showery uncertain weather, and, it may be, in particular localities; and also, to some extent, to the lack of precise definition of the type of cloud to be observed "-i.e. "the smallest and thinnest fragment of cloud that can be clearly isolated." Captain Cave mentioned some exceptions, and I others. Before the rains in India, I have often seen big clouds form and then dissolve without dropping moisture. I wrote " only for the man who, perhaps knowing nothing about scientific meteorology, desires to ascertain for himself the kind of weather he is likely to experience during the next few hours." Such a one is not likely to examine the sky when it has settled to be wet or fair. Nevertheless, even during a downpour, if he is able to isolate a little dark cloudlet under the grey pall and see it dissolve, he may, even then, predict the early probability of finer weather with fair safety. Not long ago $I$ arranged a game of golf under such conditions. I also wrote, "The nearer the cloudlet (the lower it is) the more closely do the conditions in which it floats approximate to those on the ground, and the more easily may it be observed; and, therefore, the more confident may be the prediction." Of course, therefore, I referred to ' doubtful conditions' and to the 'scud' which then occurs. My eyes, at any rate, cannot make sure of cloudlets very high in the sky, for, because of the distance, what seem to be cloudlets may be considerable clouds. Moreover, these high clouds are so remote, and the conditions in which they float so unlike those in which I stand, that observation of them can be of little utility for weather prediction. On the other hand, observation of the fact that the sky is clear for all the distance up to them gives me an indication of the continuance of fine weather.

March 9.

\section{Ancient Goins from Pondoland.}

IN Prof. Raymond Dart's article in NATURE, March 2I, 1925, p. 425, reference is made to a find of ancient coins which Prof. Dart states was made in Pondoland by Mr. Cook about fifty years ago (p. 427).

At considerable trouble I have traced these coins, and find that there are several very peculiar circumstances regarding them, which I consider throw a completely new light on the whole question.

The coins fall into three distinct groups :

(I) Ptolemaic.

(2) Late Roman.

(3) Byzantine.

Groups (I) and (2) have been accurately described by Prof. Dart. Group (3) consists of two muchdefaced coins - a small copper of Constantine II. and a large copper of John I. Now, since this last is the latest coin in the find, and it cannot be given an earlier date than A.D. 969, and since it is so worn that the obverse is completely obliterated, I suggest that the earliest possible date for the burial of the horde would be about a century later, say A.D. IO7O, by which date the Arabs were established at Sofala and were probably trading as far south as Inhambane.

Roman coins still, I believe, pass in the Peninsula, and it is quite possible that all the pieces in the find were imported by Arabs.

One most striking feature about the whole thing is the amount of wear shown by the different groups. The Ptolemaic coins are in fair condition, many of the late Roman group are almost in mint state, though others are more or less worn. The Byzantine coins, on the other hand, are so worn that I had considerable difficulty in identifying them. But when it is born in mind that the horde covers from first to last a period of more than twelve and a half centuries, one ceases to be surprised at anything.

P.O., Durban, February I6.

$$
\text { J. F. Schofield. }
$$

Uncertainty.

My exuberant friend Prof. Armstrong (Nature, Feb. 6, p. 195) seems uncertain about many things for which there is good evidence, and to glory in his uncertainty; but there is no merit in uncertainty in itself : it is just as much a sign of crankiness to reject good evidence as it is to accept bad. His attitude prevents his own enjoyment of the great discoveries of the present generation, because they do not dance to the drone of his water bagpipe-a serviceable instrument but in danger of becoming a fetish. I can only suppose that in his educational policy he has so long refrained from dogmatic instruction, and so persistently advocated other methods as more truly educative, that now he can scarcely recognise a true doctrine when he encounters it.

Yet the object of science is truth, not hesitating ignorance; and though caution is admirable it may degenerate into obscurantism. Prof. Armstrong would probably have been on the side of the orthodox in the days of Galileo, and might now justify himself by relativity; but progress and truth were on the side of Galileo nevertheless, however crude his formula. A pioneer is usually ahead of orthodoxy.

In his letter, Prof. Armstrong virtually asks me to withdraw from the Royal Society because I have gradually reached complete conviction on a subject of age-long debate and uncertainty, and have said so : while as yet the majority of Fellows still doubt. I can promise that when such a request is made officially I will resign promptly without giving trouble; but I will not refrain from stating what I firmly conceive to be the truth, as demonstrated by clear and repeated evidence, whenever such statement seems called for. If I had any uncertainty about it I would say so, but it is madness to be false to truth-no matter what the penalty may be.

Italy, February io.

\section{The Constitution of Glauconite.}

IN a recent paper (Rec. Genl. Surv. India, I925, vol. 58, pp. 330-337) Dr. L. L. Fermor proposes for glauconite a formula analogous with that already given by Clarke, which I had regarded as inadmissible (Min. Mag. I922, vol. x9, pp. 330-333). Dr. Fermor's conclusion is based on the fact that the mean of the glauconite analyses agrees with this formula. But, as he himself shows, the composition varies widely. Indeed, it would be equally logical to derive a rational formula from the mean of the published analyses of plagioclase. Dr. Fermor concludes : "It must be pointed out that . . . the formulæ given are based on averages, and that many of the individual analyses depart considerably from these formulæ." It was exactly for this reason that I felt compelled to reject the formulæ in question in favour of one which agrees almost perfectly with nine out of the twelve analyses available for this rather obscure mineral.

49 Cromwell Avenue, N.6, March I. 